\title{
Complete decomposition of polymers by means of thermally generated holes at high temperatures in titanium dioxide and its decomposition mechanism
}

\author{
Toshihiro Shinbara, Takashi Makino, Keiji Matsumoto, and Jin Mizuguchia) \\ Department of Applied Physics, Graduate School of Engineering, Yokohama National University, \\ 240-8501 Yokohama, Japan
}

(Received 25 March 2005; accepted 11 July 2005; published online 23 August 2005)

\begin{abstract}
Thermoplastic as well as thermosetting polymers are found to be completely decomposed in the presence of titanium dioxide due to thermally excited holes at high temperatures. The decomposition mechanism has therefore been investigated in terms of thermal analysis, electron-spin resonance, and infrared spectra, using polycarbonate (PC) as the model substance. The initial stage of the decomposition is the electron capture from PC by means of thermally generated holes at the $\mathrm{TiO}_{2} / \mathrm{PC}$ interface to create radicals in PC. Then, the radicals propagate throughout the PC chains to rupture the chemical bond between monomer units, leading to the remarkable reduction in molecular weight. Finally, the decomposition within the monomer unit takes place at the $\mathrm{CH}_{3}$ site to give small fragments. These fragments end up with complete combustion in the presence of oxygen to give $\mathrm{H}_{2} \mathrm{O}$ and $\mathrm{CO}_{2}$. (C) 2005 American Institute of Physics. [DOI: 10.1063/1.2030418]
\end{abstract}

\section{INTRODUCTION}

We have previously reported on a complete decomposition system of polycarbonates (used as substrate materials for optical disks) that utilizes thermally excited holes in $\mathrm{TiO}_{2}$ at high temperatures. ${ }^{1,2}$ In the area of information technologies, optical disks are more and more used for information storage systems. Polycarbonates (PC) are almost uniquely used as substrates for rewritable as well as recordable optical disks. At present, there arises a serious problem on how to dispose used optical disks. Our decomposition system is similar to the photocatalytic one which makes use of photogenerated holes for the decomposition of a variety of substances. ${ }^{3}$ On the contrary, our system features distinctly utilization of thermally excited holes at high temperatures (say, about $350{ }^{\circ} \mathrm{C}$ ) in combination with a molten state of PC, as shown in Fig. 1. This system is quite efficient because a large number of charge carriers are available at high temperatures (see Appendix A), as determined by the product of the Fermi-Dirac distribution function and the density of state. ${ }^{4}$ In addition, PC melts into liquid at these temperatures to build the "solid $\left(\mathrm{TiO}_{2}\right)$ /liquid (molten PC)" interface. This enables us to successively decompose PC into small fragments, leading to the complete combustion in the presence of oxygen to yield solely $\mathrm{H}_{2} \mathrm{O}$ and $\mathrm{CO}_{2}{ }^{2}$.

In the meantime, we have tested a variety of alternative semiconductors to $\mathrm{TiO}_{2}$ as well as polymers to be decomposed. As a matter of fact, any semiconductors can basically work if they are stable in air at high temperatures. The following semiconductors (mostly oxide ones) are found to be effective: $\mathrm{ZnO}, \mathrm{Y}_{2} \mathrm{O}_{3}, \mathrm{Cr}_{2} \mathrm{O}_{3}, \mathrm{CdS}, \mathrm{ZrO}_{2}, \mathrm{WO}_{3}, \mathrm{MoO}_{3}$, $\mathrm{Ta}_{2} \mathrm{O}_{5}, \mathrm{CuO}, \mathrm{Cu}_{2} \mathrm{O}, \mathrm{V}_{2} \mathrm{O}_{5}, \mathrm{SnO}_{2}, \mathrm{NiO}, \mathrm{Co}_{3} \mathrm{O}_{4}, \mathrm{Sb}_{2} \mathrm{O}_{3}$, and $\mathrm{MgO}$. As for polymers, $\mathrm{PC}$ is an example of the thermoplastic resins which cover polyethylene, polypropylene, polya-

${ }^{a)}$ Electronic mail: mizu-j@ynu.ac.jp mide, polyethyleneterephthalate, polystyrene, polyvinylchloride, etc. These polymers possess generally melting points and are thus confirmed to be completely decomposed in accordance with our decomposition model (Fig. 1). To our surprise, we have newly observed that even thermosetting polymers (i.e., three-dimensional polymers which have no melting point) can also entirely be decomposed. Urea, melamine, phenol, and epoxy resins fall into this category. In these polymers, the decomposition reaction is supposed to proceed, not at the "solid $\left(\mathrm{TiO}_{2}\right)$ /liquid (molten polymer)" interface, but at the "solid/solid" one. Nevertheless, the decomposition occurs as efficiently as in the case of thermoplastic resins. In this connection, the present investigation has been carried out to elucidate the decomposition mechanism of polymers, using PC as the model substance, in terms of thermogravimetric analysis/differential scanning calorimeter (TGA/DSC), electron-spin resonance (ESR), and IR

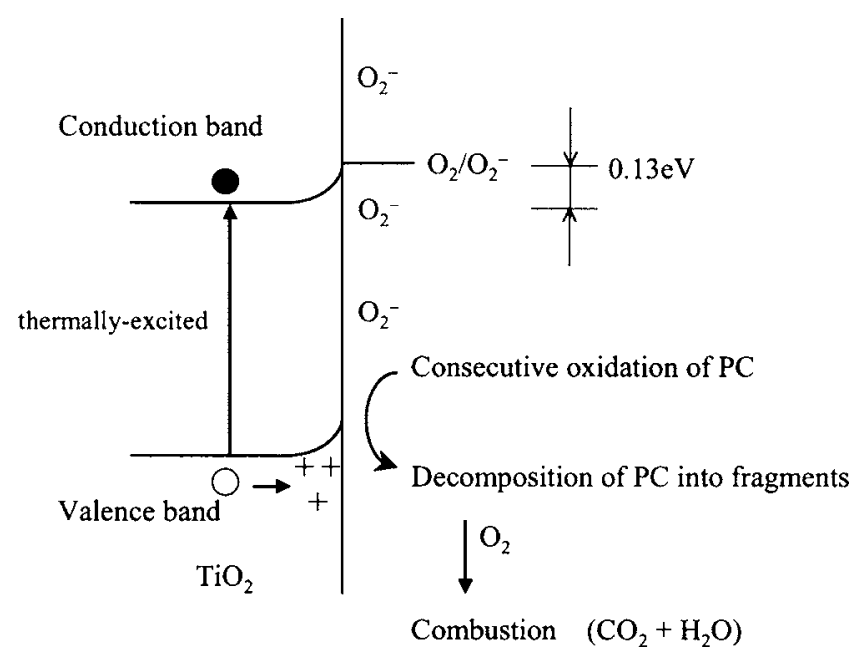

FIG. 1. Decomposition process of $\mathrm{PC}$ at the " $\mathrm{TiO}_{2} / \mathrm{PC}$ " interface by means of thermally excited holes. 
Sample A (transparent PC)

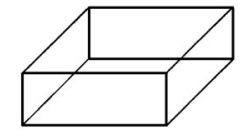

Sample B $\left(250-350^{\circ} \mathrm{C}\right)$

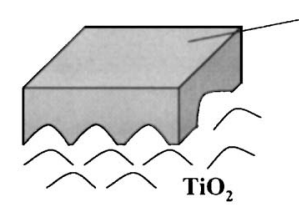

yellow via dark red to reddish glimmer (Step I )

reddish glimmer just before decomposition (Step II )

Sample C $\left(\sim 350{ }^{\circ} \mathrm{C}\right)$

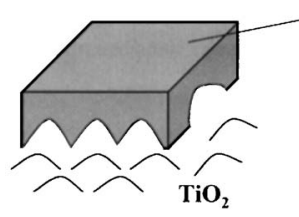

FIG. 2. Three representative samples A, B, and C: These samples are placed on $\mathrm{TiO}_{2}$ powders. PC which touches $\mathrm{TiO}_{2}$ powders are decomposed, as shown by the curved surfaces in the lower portion of the PC block.

spectra. We report here on the detailed analysis of the decomposition process of PC. Secondly, we will briefly describe the temperature dependence of electrical conductivity of $\mathrm{TiO}_{2}$ in Appendix A as well as the surface species of $\mathrm{O}_{2}^{-}$ radicals as studied by ESR in Appendix B.

\section{EXPERIMENT}

\section{A. Materials}

$\mathrm{TiO}_{2}$ powders of ST-01 designed for photocatalyst were obtained from Ishihara Sangyo Kaisha (ISK). PC of AD5503 (used for optical disks; $M_{w}=$ about 18000 ) was purchased from Teijin Chemicals.

\section{B. Measurement and equipment}

TGA was made by a Rigaku Thermo Plus 8230 on powdered samples at a heating rate of $10{ }^{\circ} \mathrm{C} / \mathrm{min}$. Heat flow was measured in air as a function of temperature by means of a (DSC) from Rigaku Ltd. (Thermo Plus: DSC8230). ESR measurement was carried out by means of an ESR spectrometer (JES-FA200) from JEOL. IR spectra were measured on an IR spectrometer (MFT-2000) from JASCO.

\section{Visual observation of the decomposition process}

With great care, we observed the decomposition process by putting a granular block $\left(1 \times 2 \times 4 \mathrm{~mm}^{3}\right)$ of polycarbonate on powders of $\mathrm{TiO}_{2}$ while heating. A schematic illustration for this process is given in Fig. 2. We found that decomposition proceeds at two sites: the first site is at the "solid/ liquid" interface where $\mathrm{TiO}_{2}$ is in contact with $\mathrm{PC}$ and the second one is the site where $\mathrm{TiO}_{2}$ does not touch PC (i.e., upper portion of the $\mathrm{PC}$ block). Upon heating, the transparent PC block was colored yellowish (around 200-250 ${ }^{\circ} \mathrm{C}$ ). Then, the color changes from yellow via dark red to reddish glimmer around $250-350{ }^{\circ} \mathrm{C}$. At this moment, the polycarbonate in contact with $\mathrm{TiO}_{2}$ powders begins gradually to be decomposed due to the "solid/liquid" reaction (step I). A moment later, noncontact area of PC passed, in an instant, out of view. In other words, $\mathrm{PC}$ was suddenly decomposed completely into $\mathrm{H}_{2} \mathrm{O}$ and $\mathrm{CO}_{2}$. This occurs around $350{ }^{\circ} \mathrm{C}$

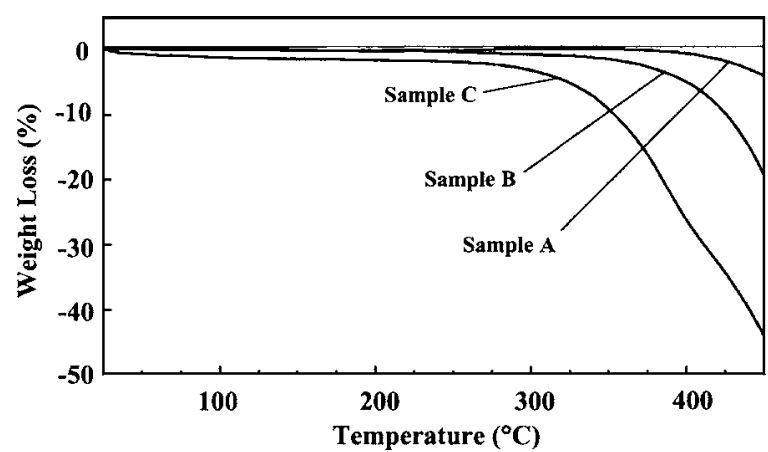

FIG. 3. TGA curves for samples A, B, and C.

(step II). An epoxy resin (i.e., a typical thermosetting polymer) behaved in a similar way. However, step I was hardly observed while step II was quite significant.

In consideration of the above process, we focus on the following three representative $\mathrm{PC}$ samples $\mathrm{A}, \mathrm{B}$, and $\mathrm{C}$ for the study of the decomposition mechanism in terms of thermal analysis (TGA/DSC), ESR, and IR spectra. Sample A is an original PC block. Sample B is a dark red block with slight reddish glimmer (around 250-350 ${ }^{\circ} \mathrm{C}$ ) and sample $\mathrm{C}$ is a reddish glimmer block just prior to decomposition (around $350{ }^{\circ} \mathrm{C}$ ). Samples B and $\mathrm{C}$ were taken from the reaction vessel by tweezers. These two samples appear black when cooled down to room temperature.

\section{RESULTS AND DISCUSSION}

\section{A. TGA/DSC measurement}

Figure 3 shows the TGA curves for samples A, B, and C. Weight loss begins at about $275^{\circ} \mathrm{C}$ in sample $\mathrm{C}, 350{ }^{\circ} \mathrm{C}$ in sample $\mathrm{B}$, and $380^{\circ} \mathrm{C}$ in sample $\mathrm{A}$. The extent of weight loss is remarkable in sample $\mathrm{C}$ and becomes less significant in sequence of samples B and A. The present result suggests that the molecular weight of PC blocks decreases in the order of samples A, B, and C. The same tendency is also recognized in DSC measurement described below. Figure 4 shows the DSC curves for samples A, B, and C. Sample A exhibits a slight endothermic process in the range between 260 and $390{ }^{\circ} \mathrm{C}$, followed by an exothermic process. On the contrary, no endothermic process is observed in samples $\mathrm{B}$ and $\mathrm{C}$. The exothermic process builds up around 150 and $250{ }^{\circ} \mathrm{C}$, re-

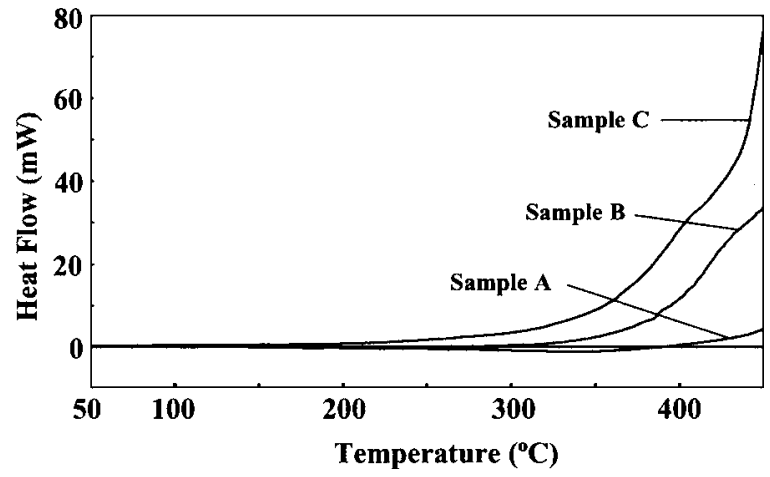

FIG. 4. DSC curves for samples A, B, and C. 


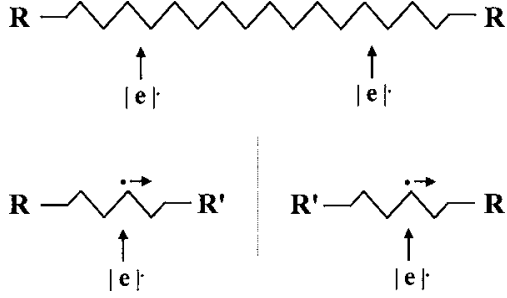

FIG. 5. Schematic illustration of the radical formation and its propagation, leading to the cleavage of the chemical bond in PC.

spectively, without any activation energy. The present DSC result indicates the reduction in molecular weight as the reaction proceeds.

In samples $\mathrm{B}$ and $\mathrm{C}$, only a lower portion of the $\mathrm{PC}$ block is in contact with $\mathrm{TiO}_{2}$ powders. Nevertheless, these appear no more transparent but black throughout the block. Furthermore, the molecular weight is diminished with the lapse of reaction time, as borne out by the TGA/DSC results. This prompted us to assume that thermally generated holes $(|e| \cdot)$ in $\mathrm{TiO}_{2}$ might capture bonding electrons from $\mathrm{PC}$ to create radicals there as shown in Fig. $5\left(|e| \cdot\left(\mathrm{TiO}_{2}\right)+e^{\prime}(\mathrm{PC})\right.$ $\rightarrow$ PC). Then, these free radicals propagate throughout the PC block (i.e., multiplication process of radical formation), leading to further disruption of the chemical bond. This finally results in the reduction of the molecular weight of PC. To verify this, the following ESR measurement was then carried out.

\section{B. ESR measurement}

Figure 6 shows the ESR signals for samples A, B, and C. No ESR signal is observed in sample A. On the other hand, ESR signal due to a radical species of $g=2.003(S=1 / 2)$ appears in sample B and increases remarkably in sample C. This indicates that the radical concentration increases rapidly as the oxidation reaction proceeds, leading to the remarkable decrease in molecular weight of PC. The existence of radicals in samples $\mathrm{B}$ and $\mathrm{C}$ is evidently attributed to the oxidation of PC by means of thermally generated holes in $\mathrm{TiO}_{2}$. In epoxy resins, exactly the same tendency was observed.

\section{IR spectra and proposed decomposition process}

As described above, the molecular weight of PC is rapidly decreased due to free radicals caused by thermally gen-

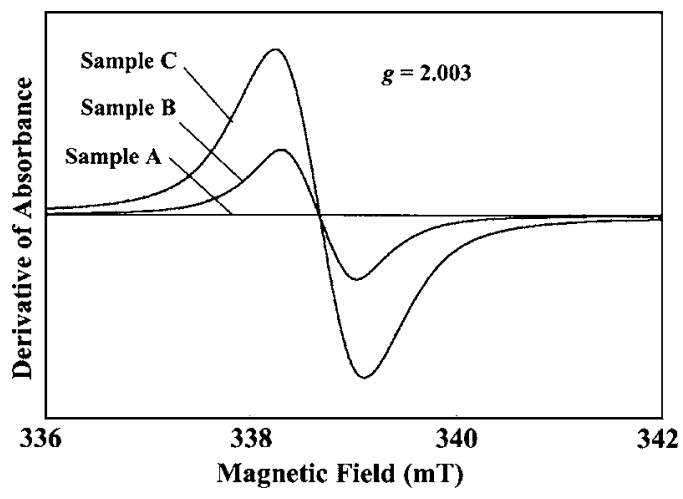

FIG. 6. ESR spectra for samples A, B, and C.

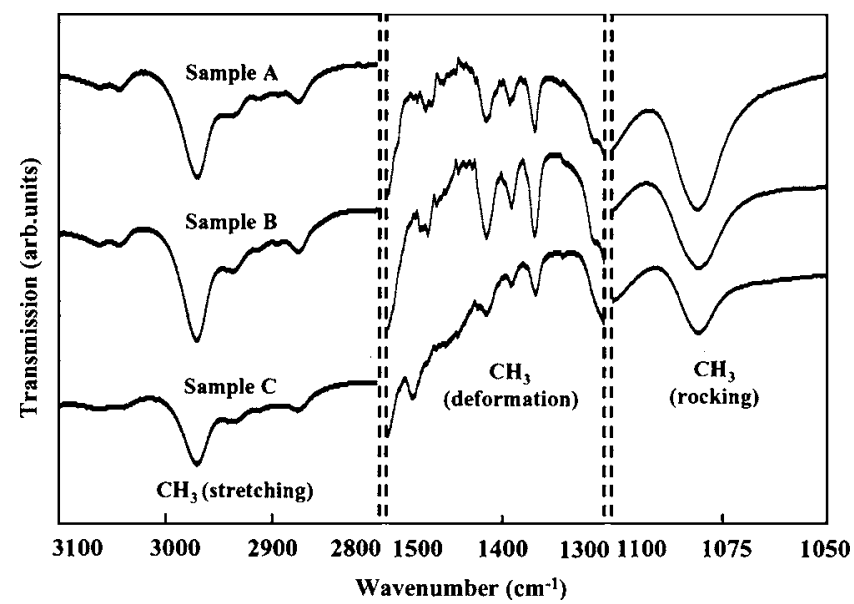

FIG. 7. IR spectra for samples A, B, and C.

erated holes in $\mathrm{TiO}_{2}$. The reduction in molecular weight is closely related to the disruption of the PC chains. This presumably occurs at a site between monomer units while the monomer conformation is still retained. The present assumption is supported by the following IR spectra for samples A, $\mathrm{B}$, and $\mathrm{C}$. Figure 7 shows the IR spectra of the $\mathrm{CH}_{3}$ stretching $\left(2950 \mathrm{~cm}^{-1}\right)$, deformation $\left(\sim 1300 \mathrm{~cm}^{-1}\right)$, and rocking vibrations $\left(\sim 1100 \mathrm{~cm}^{-1}\right)$. The absorption intensities in these characteristic bands remain intact in samples $\mathrm{A}$ and $\mathrm{B}$, although the molecular weight is diminished in sample B. This suggests that the molecular conformation within the monomer unit is still retained. On the other hand, the $\mathrm{CH}_{3}$ characteristic bands become weaker in sample $\mathrm{C}$ as compared with those of samples A and B. This implies that the skeleton of the monomer unit starts decomposing at the $\mathrm{CH}_{3}$ site. As schematically summarized in Fig. 8, the first step of the decomposition in PC occurs at the bond between monomer units while the monomer conformation is retained. Then, the $\mathrm{CH}_{3}$ site begins to be decomposed in the second step. This results in the fragmentation of $\mathrm{PC}$ and the fragments are then burnt completely in the presence of $\mathrm{O}_{2}$ to give $\mathrm{H}_{2} \mathrm{O}$ and $\mathrm{CO}_{2}{ }^{2}$

The above decomposition process is actually initiated by electron capture (i.e., formation of a radical in PC) at the " $\mathrm{TiO}_{2} / \mathrm{PC}$ " interface by means of thermally generated holes.

Step I : Cleavage between monomer units

(a)

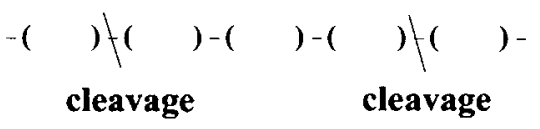

Step II : Decomposition within the monomer unit

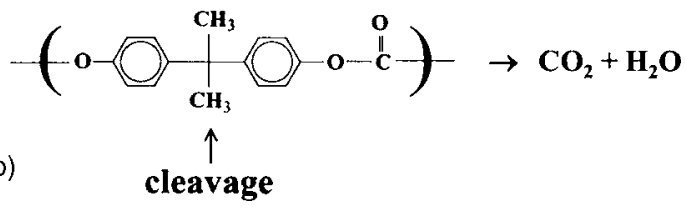

FIG. 8. Schematic illustration of the decomposition process: (a) step I: cleavage between monomer units and (b) step II: cleavage at the methyl groups within the monomer unit. 
Decomposition occurs most effectively where $\mathrm{TiO}_{2}$ is in contact with $\mathrm{PC}$ which is in the molten state at high temperatures. In parallel, the propagation of radicals takes place throughout the lower portion of PC block that is in the molten state, as well as the PC block which does not touch $\mathrm{TiO}_{2}$. In this way, the entire PC can totally be decomposed in the presence of $\mathrm{TiO}_{2}$. It is likely that the same mechanism is operative in all thermoplastic polymers other than PC. It is also to be noted that the decomposition process which occurs in noncontact areas with $\mathrm{TiO}_{2}$ seems to play an important role in thermosetting polymers as represented by epoxy resins. The initiation of the radical formation in thermosetting polymers is mostly made by collision contact between $\mathrm{TiO}_{2}$ and polymers. Therefore, some retention time is required for thermosetting polymers to set the decomposition in operation.

\section{CONCLUSIONS}

The decomposition mechanism of PC by means of thermally generated holes has been investigated from the standpoint of radical formation in PC. The initial stage is the formation of radicals in $\mathrm{PC}$ due to the thermally excited holes at the $\mathrm{TiO}_{2} / \mathrm{PC}$ interface. This process is very efficient because $\mathrm{PC}$ is in the molten state at high temperatures. This leads to the PC decomposition at the contact between $\mathrm{TiO}_{2}$ and PC. At the same time, the radicals generated in PC propagate throughout the $\mathrm{PC}$ chains to rupture the chemical bond between monomer units, leading to the remarkable reduction in molecular weight. Finally, the decomposition within the monomer unit takes place at the $\mathrm{CH}_{3}$ site to give small fragments. These fragments end up with complete combustion in the presence of oxygen to give $\mathrm{H}_{2} \mathrm{O}$ and $\mathrm{CO}_{2}$. A similar mechanism is also operative in thermosetting polymers, although the "solid $\left(\mathrm{TiO}_{2}\right) /$ solid (polymer)" reaction requires some retention time.

\section{APPENDIX A: TEMPERATURE DEPENDENCE OF THE ELECTRICAL CONDUCTIVITY MEASURED ON A SINGLE CRYSTAL OF $\mathrm{TIO}_{2}$}

The number of charge carriers is given by the product of the Fermi-Dirac distribution function and the density of state. ${ }^{4}$ A rough estimate of the ratio between the charge carrier concentration $\left(n_{\mathrm{RT}}\right)$ at room temperature and that $\left(n_{623 \mathrm{~K}}\right)$ at $350{ }^{\circ} \mathrm{C}$ gives $n_{623 \mathrm{~K}} / n_{\mathrm{RT}} \approx 8.8 \times 10^{13}$ where the band gap of titanium dioxide of the rutile phase is $3.2 \mathrm{eV} .^{2}$ In order to approximately examine the actual ratio between room temperature and $350{ }^{\circ} \mathrm{C}$, the temperature dependence of the conductivity has been measured on a single crystal of $\mathrm{TiO}_{2}$. A single-crystal plate of the rutile form $\left[10 \times 10 \times 0.5 \mathrm{~mm}^{3}\right.$ : (100) plane] was purchased from Shinkosha, Japan. Measurement was made in air with a structure of $\mathrm{Al} / \mathrm{TiO}_{2} / \mathrm{Al}$ at a heating rate of $10{ }^{\circ} \mathrm{C} / \mathrm{min}$. The sample was kept in the dark for three days before measurement. The sample exhibits an initial resistivity of $3.1 \times 10^{11} \Omega \mathrm{cm}$ at room temperature. Then, the resisitivity was remarkably decreased with increasing temperature to give a value of $150 \Omega \mathrm{cm}$. Approximately, a resistivity decrease of about ten orders of magnitude was

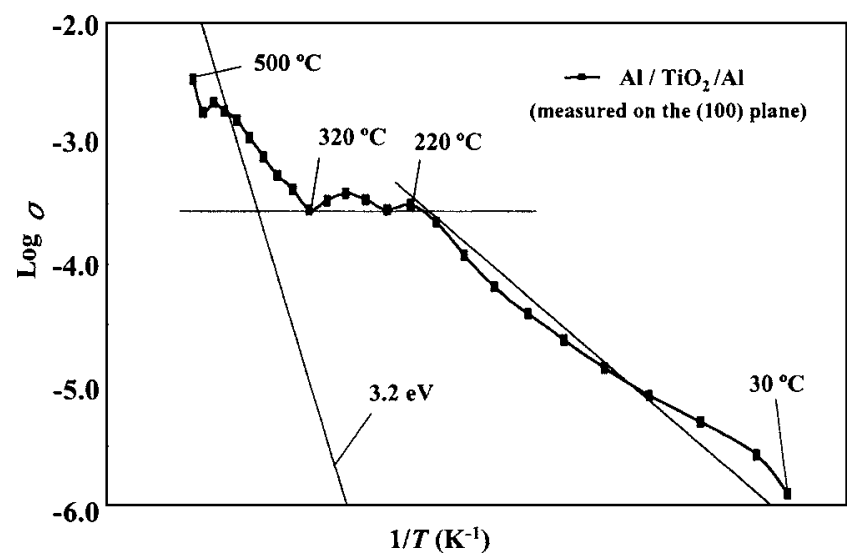

FIG. 9. Temperature dependence of the electrical conductivity measured on a single crystal of $\mathrm{TiO}_{2}$ (rutile phase).

observed. After cooling the sample, the measurement was repeated for the second run. However, the initial resistivity was about $4.5 \times 10^{6} \Omega \mathrm{cm}$ while the final one at $350{ }^{\circ} \mathrm{C}$ was again around $150 \Omega \mathrm{cm}$. The poor reproducibility of the electrical conductivity in $\mathrm{TiO}_{2}$ is a well-known effect, especially when the sample is heat cycled or exposed to the ambient light. However, the original electrical characteristics recovered when the sample was kept again in the dark for three days.

Since $\mathrm{TiO}_{2}$ is usually used indoor or outdoor, the temperature dependence of the above sample was measured under normal illumination in the laboratory. Figure 9 shows the Arrehnius plot of the electrical conductivity. In this plot, a gradient of $3.2 \mathrm{eV}$ is recognized in the intrinsic region. Approximately, a conductivity change of three to four orders of magnitude was observed.

\section{APPENDIX B: BAND BENDING AT THE "SOLID/AIR" INTERFACE AT HIGH TEMPERATURES}

As shown in Fig. 1, the upward bending of $\mathrm{TiO}_{2}$ at the solid/air interface is normally operative due to the adsorbed $\mathrm{O}_{2}^{-}$radicals $\left[\mathrm{O}_{2}(\mathrm{gas})+e^{\prime} \rightarrow \mathrm{O}_{2}^{-}(\mathrm{ads})\right]^{5,6}$ The existence of the $\mathrm{O}_{2}^{-}$radical has already been verified by electron-spinresonance (ESR) measurements. ${ }^{7,8}$ The adsorbate $\mathrm{O}_{2}^{-}$then causes the upward band bending to occur that facilitates the accumulation of holes at the surface. However, it is likely

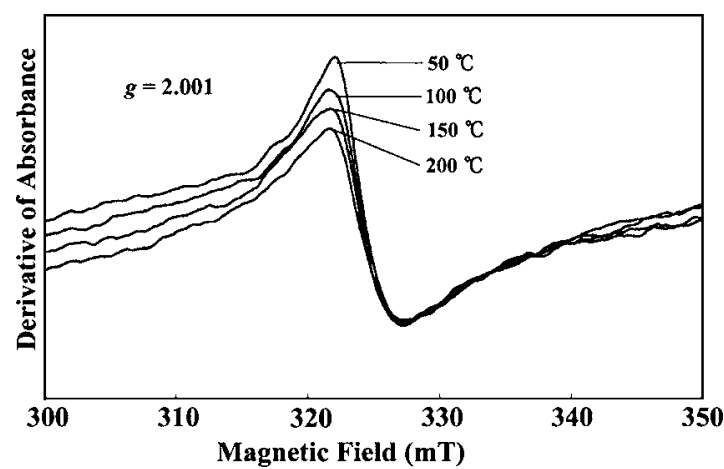

FIG. 10. Temperature dependence of ESR spectra of $\mathrm{TiO}_{2}$ measured on powders from 50 to $200{ }^{\circ} \mathrm{C}$ in steps of $50^{\circ}$. 
that the band bending decreases due to desorption of $\mathrm{O}_{2}^{-}$ (ads) at high temperatures $\left[\mathrm{O}_{2}^{-}(\right.$ads $) \rightarrow \mathrm{O}_{2}($ gas $\left.)+e^{\prime}\right]$. It is, however, also possible that the $\mathrm{O}_{2}$ (gas) can newly be adsorbed $\left[\mathrm{O}_{2}^{-}(\mathrm{ads})\right]$ by capturing thermally generated electrons in the conduction band. This enhances the band bending. Desorption and adsorption are presumably in thermal equilibrium at high temperatures. In order to gain more insight into the $\mathrm{O}_{2}^{-}$(ads) concentration at elevated temperatures, the temperature dependence of ESR signals has been studied.

Figure 10 shows the temperature dependence of ESR signals measured on powders of $\mathrm{TiO}_{2}$ at temperatures of 50, 100,150 , and $200^{\circ} \mathrm{C}$. The ESR signal decreases slightly as the temperature is increased. However, even at $200{ }^{\circ} \mathrm{C}$, roughly $75 \%$ of the $\mathrm{O}_{2}^{-}$(ads) concentration at room temperature is retained. This indicates clearly that the band bending is still assured even at $200{ }^{\circ} \mathrm{C}$. This leads to the efficient hole diffusion from the bulk to the surface.

${ }^{1}$ J. Mizuguchi, J. Electrochem. Soc. 148, J55 (2001).

${ }^{2}$ J. Mizuguchi and T. Shinbara, J. Appl. Phys. 96, 3514 (2004).

${ }^{3}$ R. Wang, K. Hashimoto, A. Fujishima, M. Chikuni, E. Kojima, A. Kitamura, M. Shimohigoshi, and T. Watanabe, Nature (London) 388, 431 (1997).

${ }^{4}$ C. Kittel, Introduction to Solid State Physics, 6th ed. (Wiley, New York, 1986).

${ }^{5} \mathrm{~K}$. Hauffe and S. Roy Morrison, Adsorption (Walter de Gruyter, Hawthorne, New York, 1974).

${ }^{6} \mathrm{~S}$. R. Morrison, in Surface Physics of Phosphors and Semiconductors, edited by C. G. Scott and C. E. Reed (Academic, New York, 1975), Chap. 4.

${ }^{7}$ C. Naccache, P. Meriandean, M. Che, and T. Tench, Trans. Faraday Soc. 67, 506 (1971).

${ }^{8}$ K. M. Sancier, J. Catal. 9, 331 (1968). 